\title{
Influenza A virus-derived siRNAs increase in the absence of NS1 yet fail to inhibit virus replication
}

\author{
KEVIN TSAI, DAVID G. COURTNEY, EDWARD M. KENNEDY, ${ }^{1}$ and BRYAN R. CULLEN \\ Department of Molecular Genetics and Microbiology, Duke University Medical Center, Durham, North Carolina 27710, USA
}

\begin{abstract}
While the issue of whether RNA interference (RNAi) ever forms part of the antiviral innate immune response in mammalian somatic cells remains controversial, there is considerable evidence demonstrating that few, if any, viral small interfering RNAs (siRNAs) are produced in infected cells. Moreover, inhibition of RNAi by mutational inactivation of key RNAi factors, such as Dicer or Argonaute 2, fails to enhance virus replication. One potential explanation for this lack of inhibitory effect is that mammalian viruses encode viral suppressors of RNAi (VSRs) that are so effective that viral siRNAs are not produced in infected cells. Indeed, a number of mammalian VSRs have been described, of which the most prominent is the influenza A virus (IAV) NS1 protein, which has not only been reported to inhibit RNAi in plants and insects but also to prevent the production of viral siRNAs in IAV-infected human cells. Here, we confirm that an IAV mutant lacking NS1 indeed differs from wild-type IAV in that it induces the production of readily detectable levels of Dicer-dependent viral siRNAs in infected human cells. However, we also demonstrate that these siRNAs have little if any inhibitory effect on IAV gene expression. This is likely due, at least in part, to their inefficient loading into RNA-induced silencing complexes.
\end{abstract}

Keywords: influenza A virus; siRNA; RNA interference; antiviral response; NS1 protein

\section{INTRODUCTION}

While RNA interference (RNAi) almost certainly initially developed as an antiviral mechanism, and remains an important antiviral defense in plants, nematodes and invertebrates, the role of RNAi in antiviral defense in mammalian cells remains controversial (Cullen et al. 2013). One predicted hallmark of antiviral RNAi is the detection of $22 \pm 1$ nucleotide (nt) long RNAs in infected cells that originate from viral double stranded RNAs (dsRNAs) that have been cleaved by the cellular exonuclease Dicer (Dcr). These small RNAs in turn serve as guide RNAs for the cellular RNA-induced silencing complex (RISC), the key component of which is the "slicer" enzyme Argonaute 2 (Ago2) (Hannon 2002). However, deep sequencing of small RNA populations in mammalian cells infected by a wide range of pathogenic viruses, including several RNA viruses that replicate their genome via long dsRNA intermediates that should be ideal Dcr substrates, has failed to detect significant levels of viral siRNAs (Pfeffer et al. 2005; Parameswaran et al. 2010; Backes et al. 2014; Bogerd et al. 2014; Girardi et al. 2015; Li et al. 2016). Moreover, neither mutational inactivation of the Dcr enzyme by gene editing, which blocks the expression of not only siRNAs but also microRNAs (miRNAs), nor inactivation of Ago2, which

${ }^{1}$ Present address: Oncorus, Cambridge, Massachusetts 02139, USA Corresponding author: bryan.cullen@duke.edu

Article is online at http://www.rnajournal.org/cgi/doi/10.1261/rna.066332. 118. should block RNAi, has any effect on the replication of a range of RNA viruses in human somatic cells (Backes et al. 2014; Bogerd et al. 2014; Maillard et al. 2016).

One possible explanation for these observations is that the single Dcr enzyme expressed in mammalian somatic cells is unusual in being incapable of cleaving viral dsRNAs effectively. Evidence in support of this hypothesis comes from the observation that embryonic stem (ES) cells and oocytes appear able to generate viral siRNAs more effectively than somatic cells (Wianny and Zernicka-Goetz 2000; Billy et al. 2001; Babiarz et al. 2008; Tam et al. 2008; Watanabe et al. 2008; Nejepinska et al. 2012; Stein et al. 2015 ) and, at least in rodents, it has been demonstrated that oocytes naturally express an amino-terminally truncated isoform of Dcr that processes ectopically expressed dsRNAs into functional siRNAs more efficiently than does full-length murine Dcr (Flemr et al. 2013). This result has also been reproduced in human cells using an artificial, amino-terminally truncated mutant of human Dcr (hDcr), called hDcr N1 (Kennedy et al. 2015). Alternatively, it has also been proposed that the type I interferon pathway, and specifically the RIG-I-like receptor LGP2, actively inhibits the processing of long dsRNAs by Dcr

(C) 2018 Tsai et al. This article is distributed exclusively by the RNA Society for the first 12 months after the full-issue publication date (see http:// rnajournal.cshlp.org/site/misc/terms.xhtml). After 12 months, it is available under a Creative Commons License (Attribution-NonCommercial 4.0 International), as described at http://creativecommons.org/licenses/by-nc/4.0/. 
(Maillard et al. 2016; van der Veen et al. 2018). Of note, because oocytes and ES cells are not able to mount an interferon response (Wang et al. 2013), this hypothesis provides an attractive explanation for why these undifferentiated cell types are RNAi competent. Finally, it has been proposed that activation of protein-based innate signaling pathways by viral infection can inhibit RISC activity by inducing the poly-ADP-ribosylation of RISC-associated proteins such as Ago2 (Seo et al. 2013). However, it has also been reported that RISC is fully active in virally infected cells, including cells infected by influenza A virus (IAV) (Benitez et al. 2015), and a number of reports have documented that miRNAs, which are loaded into RISC and function via the same mechanisms as siRNAs in mammalian cells (Zeng et al. 2003), can effectively restrict the replication of a range of viruses if these are modified to contain perfectly complimentary target sites (Barnes et al. 2008; Kelly et al. 2008; Ylösmäki et al. 2008; Perez et al. 2009).

An alternative hypothesis to explain the inability of mammalian cells to mount an effective RNAi response to viral infection proposes that viruses encode viral suppressors of RNA silencing (VSRs) that are so potent that virus-infected cells produce almost no viral siRNAs (Ding 2010; Li et al. 2016). Indeed, a number of VSRs have been described, including the VP35 protein encoded by Ebola virus (Haasnoot et al. 2007; Fabozzi et al. 2011), the VA1 noncoding RNA encoded by adenovirus ( $\mathrm{Lu}$ and Cullen 2004; Andersson et al. 2005), the $3 \mathrm{~A}$ protein encoded by human enterovirus 71 (Qiu et al. 2017) and, most prominently, the nonstructural protein 1 (NS1) encoded by IAV (Bucher et al. 2004; Delgadillo et al. 2004; Li et al. 2004). Indeed, in a recent paper it was reported that an NS1-deficient IAV mutant produced a substantial level of hDcr-dependent siRNAs in infected cells and it was further proposed, based on the use of murine cells lacking a functional form of the key RNAi-effector Ago2, that these siRNAs can inhibit IAV replication (Li et al. 2016). Here, we demonstrate that an NS1-deficient IAV mutant indeed produces a significantly higher level of IAV-derived siRNAs than does wild-type IAV in infected human somatic cells but we also demonstrate that these siRNAs do not, in fact, significantly repress IAV gene expression. This lack of detectable antiviral activity may be at least partly due to inefficient loading of IAV-derived siRNAs into RISC.

\section{RESULTS}

\section{Loss of NS1 increases the production of viral siRNAs in IAV-infected cells}

Previously, it has been reported that wild-type IAV does not generate a significant level of viral siRNAs in infected somatic cells (Perez et al. 2010; Umbach et al. 2010; Backes et al. 2014) and moreover that IAV replication is not enhanced by mutational inactivation of the endogenous $\mathrm{hDcr}$ protein (Bogerd et al. 2014), thus indicating that RNAi does not normally in- hibit wild-type IAV replication. However, it has also recently been proposed that an IAV mutant lacking the NS1 protein can generate significant levels of viral siRNAs that could potentially inhibit IAV replication ( $\mathrm{Li}$ et al. 2016). Therefore, we generated stocks of wild-type IAV strain A/Puerto Rico/8/1934 (PR8), along with a previously described PR8 mutant $(\triangle \mathrm{NS} 1)$ entirely lacking the NS1 protein but retaining the NEP protein encoded on the NS1 genome segment (García-Sastre et al. 1998). We also generated stocks of a second PR8 mutant, bearing a point mutation in NS1 (R38A), which has been reported to abolish the dsRNA binding activity of NS1 (Wang et al. 1999). We then infected wild-type $293 \mathrm{~T}$ cells with these three virus stocks at an MOI of 0.1 under nonspreading conditions, i.e., in the absence of trypsin in the media. The infected cultures were harvested at $24 \mathrm{~h}$ postinfection (hpi) and small RNAs (<200 nt) collected and subjected to deep sequencing, as previously described (Kennedy et al. 2015). This resulted in the recovery of between $1.2 \times 10^{7}$ and $1.0 \times 10^{7}$ reads $18-26 \mathrm{nt}$ in length that could either be identified as known human miRNAs or that derived from IAV. As shown in Figure 1A, there were essentially no reads of IAV origin, in the $22 \pm 1$ nt size range characteristic of siRNAs, recovered from the culture infected with wild-type IAV although we did recover a number of $\sim 26 \mathrm{nt}$ long reads, originating exclusively from the vRNA strand, that likely represent the previously described $\sim 26$ nt viral leader RNAs (leRNAs) expressed by IAV (Perez et al. 2010; Umbach et al. 2010). In contrast, in the culture infected with the $\triangle$ NS1 IAV mutant, we recovered a readily detectable level of siRNAs, of both positive and negative polarity, that derive from IAV transcripts and that were almost entirely 21-23 nt in length (Fig. 1B). These viral siRNAs contributed $\sim 0.56 \%$ of the total assignable small RNA pool, defined as consisting of viral siRNAs and cellular miRNAs, which, given that the MOI used was 0.1 , implies that IAV siRNA could contribute as much as $5 \%$ of the total small regulatory RNA population on an individual cell basis. Because hDcr functions as a dsRNA-specific exonuclease (Hannon 2002), the viral siRNAs identified in Figure 1B should originate from the termini of the eight IAV gene segments, as siRNAs are predicted to arise by hDcr cleavage from the termini of each of the viral dsRNA replication intermediates. Indeed, this is exactly what was observed (Fig. 1C-J), though the $5^{\prime}$ end of the positive sense IAV RNAs, and $3^{\prime}$ end of the IAV vRNAs, were the primary sources of siRNAs. Interestingly, and as also reported previously ( $\mathrm{Li}$ et al. 2016), we recovered far more siRNAs from the residual NS1 segment than from any other viral genome segment in these $\Delta$ NS1 mutant infected cells.

To verify these data in an alternative, more physiologically relevant human cell type, we also infected the lung epithelial cell line A549 with WT PR8, or the $\triangle$ NS1 PR8 mutant, at an MOI of 2.5. We then harvested total small RNAs $(<200 \mathrm{nt})$ at $24 \mathrm{hpi}$ and again subjected these to deep sequencing. Similar to what was seen in $293 \mathrm{~T}$ cells, only background levels of $22 \pm 1 \mathrm{nt}$ virus-derived reads were found in WT 

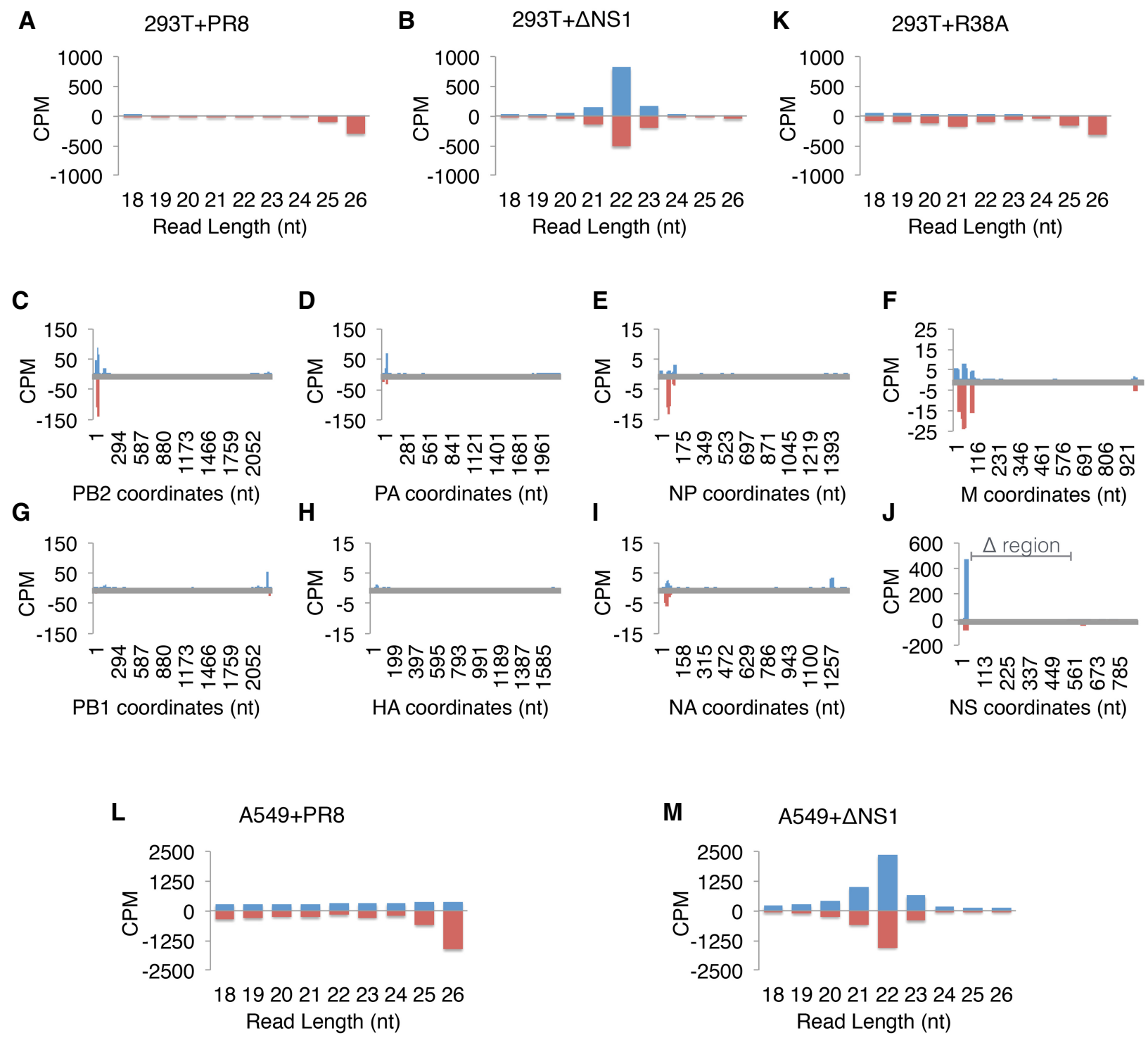

FIGURE 1. Endogenous hDcr can produce IAV-derived siRNAs, but only in the absence of NS1 expression. 293T cells were infected with an MOI of 0.1 with wild-type PR8 IAV, $\triangle \mathrm{NS1}$, or the NS1-R38A mutant virus. Cells were harvested $24 \mathrm{~h}$ post-infection (hpi), small RNAs collected and then subjected to deep sequencing. The size distribution of IAV-aligning sequencing reads were plotted for $(A)$ wild-type PR8, $(B) \Delta$ NS1, and (K) NS1-R38A-infected 293T cells, shown in counts per million assignable reads (CPM). Reads that aligned to positive sense viral RNAs are shown in blue while negative sense vRNA-aligning reads are shown in red. $(C-J)$ The sites of origin of viral siRNAs produced in $\Delta$ NS1-infected 293T cells (panel $B$ ) were mapped for each viral RNA segment, with positive and negative sense reads shown in blue and red as before. The $y$-axis scales were varied to accommodate the varying counts found for each IAV gene segment. The absence of reads from coordinates 57-528 on the NS segment in $J$ results from the deletion of the corresponding region in the $\triangle$ NS1 virus. $(L, M)$ A549 cells were infected at an MOI of 2.5 using wild-type PR8 or the $\triangle$ NS1 PR8 mutant virus. Small RNAs from cells harvested 24 hpi were sequenced and the size distribution of IAV-aligning reads plotted for $(L)$ wildtype PR8 infected and $(M) \Delta$ NS1 infected A549 cells, as described above.

PR8-infected cells, with the $\sim 26 \mathrm{nt}$ leRNAs once again apparent (Fig. 1L); while virus-aligning reads of the siRNA size range were again readily detectable in A549 cells infected with the $\triangle$ NS1 IAV mutant (Fig. 1M). Interestingly, in this infection with an MOI of 2.5 (thus 92\% of cells should be infected), the $\triangle$ NS1 virus-derived siRNAs contributed $\sim 4.7 \%$ of the total siRNA+miRNA population, similar to the $\sim 5 \%$ per cell estimate derived from the $293 \mathrm{~T}$ infection shown in Figure 1B. Plotting the $\Delta$ NS1 virus-derived siRNA reads onto the various IAV genome segments revealed that the IAV-derived small RNAs produced in A549 cells were again almost exclusively derived from the termini of these viral RNAs (data not shown).

It has been reported that the dsRNA binding domain of NS1 is required for inhibition of siRNA production in plants (Bucher et al. 2004), and dsRNA binding has been reported to be important for the function of a range of plant virus VSRs (Lichner et al. 2003; Mérai et al. 2006). We therefore wished 
to test whether dsRNA binding was also required for inhibition of siRNA biogenesis by NS1 in IAV infected cells. Previously, it has been reported (Wang et al. 1999) that mutagenesis of the arginine residue located at position 38 in NS1 is sufficient to block dsRNA binding without affecting NS1 dimerization. We therefore generated an IAV mutant in which the arginine at position 38 in NS1 was mutated to alanine (R38A) and tested whether this viral mutant would indeed phenocopy the $\triangle$ NS1 deletion mutant. Surprisingly, the R38A virus actually produced very few siRNAs in infected $293 \mathrm{~T}$ cells (Fig. 1K). We therefore conclude either that dsRNA binding is not critical for inhibition of viral siRNAs production by NS1 in IAV-infected human cells or that the R38A mutant actually does retain some or all of its ability to bind dsRNAs.

We note that the WT IAV virus stock used was produced in embryonated chicken eggs while the $\Delta \mathrm{NS} 1$ virus stock was grown in NS1-expressing MDCK cells, thus raising the concern that the difference in siRNA production observed with these viruses (Fig. 1A,B) was due to this different origin. However, as the R38A IAV mutant stock was also grown in NS1-expressing MDCK cells, yet behaves essentially the same as WT IAV in terms of viral siRNA production (Fig. 1 , cf. A and $\mathrm{K}$ ), this potential concern is eliminated.

\section{Viral siRNAs produced in IAV-infected cells are Dicer dependent}

We next asked whether the viral siRNAs produced in IAVinfected wild-type $293 \mathrm{~T}$ cells are, in fact, hDcr-dependent and also whether the previously described hyperactive $\mathrm{hDcr}$ N1 mutant (Kennedy et al. 2015) would be able to generate a greater number of IAV-derived siRNAs than wild-type hDcr. For this purpose, we used the previously described NoDice cell line (Bogerd et al. 2014; Kennedy et al. 2015), a 293T derivative in which the $d c r$ gene has been mutationally inactivated by gene editing. Importantly, we have previously shown that NoDice cells replicate IAV at a level that is comparable to wild-type 293T cells (Bogerd et al. 2014). As shown in Figure 2A, and as expected, infection of NoDice cells with wild-type IAV strain PR8 at an MOI of 0.1 did not result in the detection of any viral siRNAs, though the IAV leRNAs, which do not originate from hDcr cleavage, could again be detected. As shown in Figure 2B, transfection of the NoDice cells with the wild-type hDcr expression plasmid pK-WT resulted in the detection of a low but significant level of IAV siRNAs in the expected $22 \pm 1$ size range (we note that the level of hDcr expression in these transfected NoDice cells is much higher than in wild-type 293T-see below). As expected, expression of the hDcr N1 mutant induced an $~ 3.6$-fold increase in the production of IAV siRNAs in wild-type PR8 infected NoDice cells, relative to cells expressing ectopic wild-type hDcr (Fig. 2C).

We next analyzed siRNA production by the $\triangle$ NS1 IAV mutant under these same conditions. As shown in Figure
2D, infection of NoDice cells, in the absence of ectopic $\mathrm{hDcr}$, again resulted in the production of no viral siRNAs. However, when we transfected the NoDice cells with the wild-type hDcr expression vector pK-WT, we observed the readily detectable production of IAV siRNAs, of both polarities and of the predicted $22 \pm 1$ size (Fig. 2E). In fact, we observed an $\sim 5.5$-fold increase in the relative level of IAV siRNAs in the $\triangle$ NS1-infected cells, compared to the wildtype IAV analyzed in Figure 2B, when normalized to the level of endogenous miRNA expression. We detected an even more dramatic effect when we ectopically expressed the N1 hDcr mutant in the NoDice cells and then infected them with the $\Delta$ NS1 mutant (Fig. 2F-note the change in the $y$-axis scale). The relative increase in siRNA production, relative to the wild-type IAV-infected culture shown in Figure 2C, was an impressive $\sim 8.2$-fold. Alignment of the IAV siRNA reads shown in Figure 2E to the eight IAV genome segments again confirmed their origin from both termini of the predicted dsRNA genomic replication intermediates (Fig. 2G-N). Of note, these small RNA deep sequencing data also confirmed the predicted absence of any human miRNA reads in the NoDice cell line (Fig. 2O) and confirmed that ectopic expression of either wild-type or $\mathrm{N} 1 \mathrm{hDcr}$ rescued miRNA biogenesis effectively (Fig. 2P,Q), as also previously reported (Bogerd et al. 2014).

\section{Viral siRNAs produced in IAV-infected cells fail to inhibit viral gene expression}

The key question is, of course, whether mutational inactivation of the IAV NS1 gene, and the concomitant increase in IAV-derived siRNAs (Fig. 2) indeed results in siRNA-mediated repression of IAV gene expression. To address this issue, we transfected wild-type $293 \mathrm{~T}$ cells or NoDice cells with either the control $\mathrm{pK}$ empty vector or with $\mathrm{pK}$ variants expressing wild-type hDcr or the $\mathrm{N} 1 \mathrm{hDcr}$ mutant. At $3 \mathrm{~d}$ post-transfection, the cultures were infected with either the wild-type or $\triangle \mathrm{NS1}$ variant of IAV strain PR8 at an MOI of 1.0. A further $24 \mathrm{~h}$ later, the cells were harvested for analysis of protein expression, by western blot, or mRNA/vRNA expression, by qRT-PCR. Representative western blots are shown in Figure $3 \mathrm{~A}$ and $\mathrm{F}$ while protein and RNA data derived from multiple independent replicates is shown in Figure 3B-E and G-J. As may be observed in Figure. 3A and $\mathrm{F}$, ectopic overexpression of wild-type hDcr or N1 $\mathrm{hDcr}$ did not exert a marked or consistent inhibitory effect on the level of IAV gene expression in either the presence or absence of NS1, as determined by western blot for expression of the IAV HA, NP, M1, or M2 protein, even though the data shown in Figure 2 demonstrate that loss of NS1 results in a substantial increase in the production of viral siRNAs, especially in cells expressing ectopic $\mathrm{N} 1 \mathrm{hDcr}$. We note that, while the ectopically expressed wild-type and N1 hDcr proteins are readily detectable in the transfected 293T cells by western blot, the endogenous hDcr protein is not. 


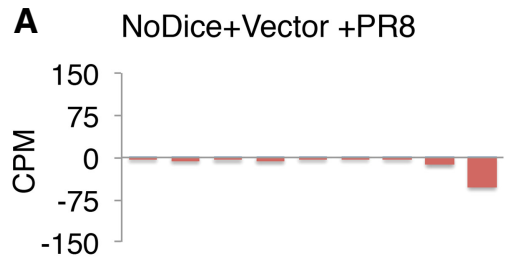

181920212223242526 Read Length (nt)

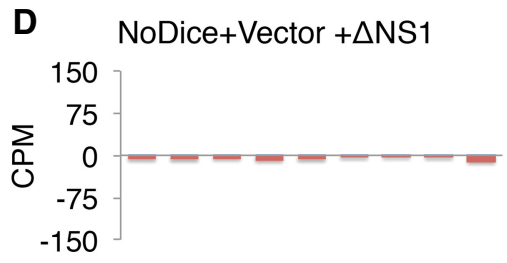

181920212223242526 Read Length (nt)

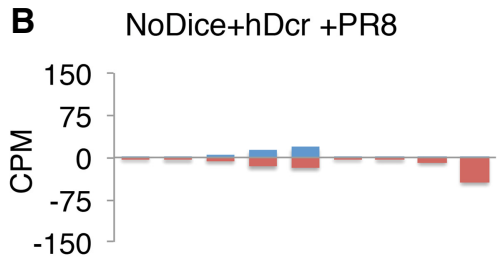

181920212223242526 Read Length (nt)

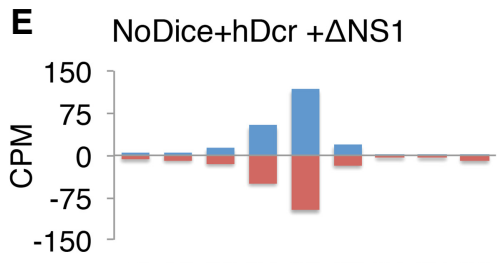

181920212223242526 Read Length (nt)

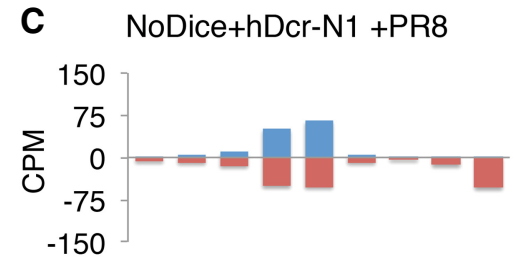

181920212223242526 Read Length (nt)

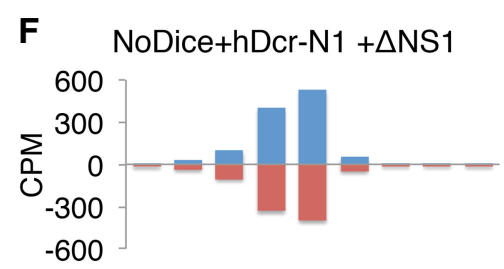

181920212223242526 Read Length (nt)
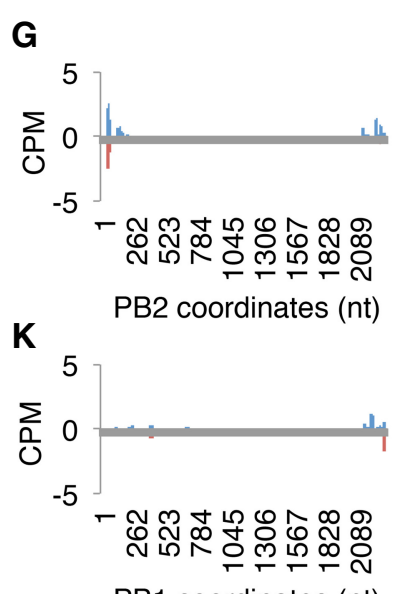

PB1 coordinates (nt)

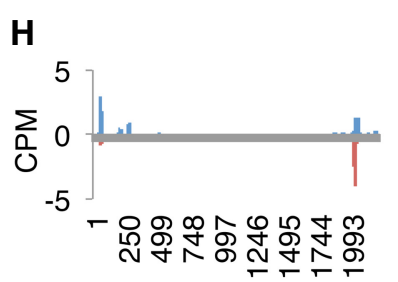

PA coordinates (nt)

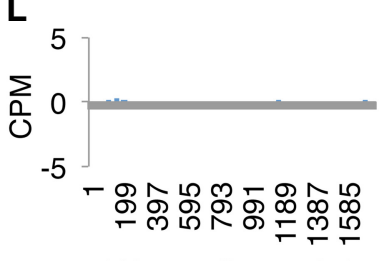

HA coordinates (nt)

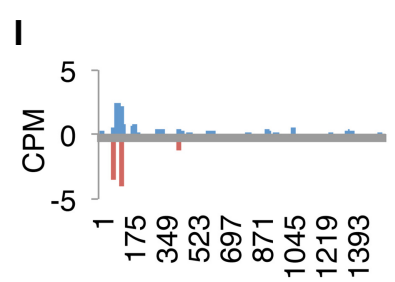

NP coordinates (nt)

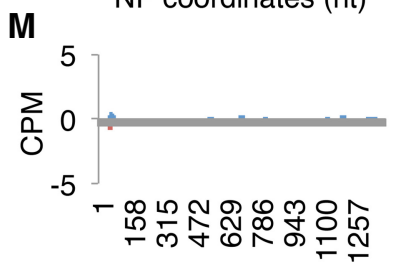

NA coordinates (nt)
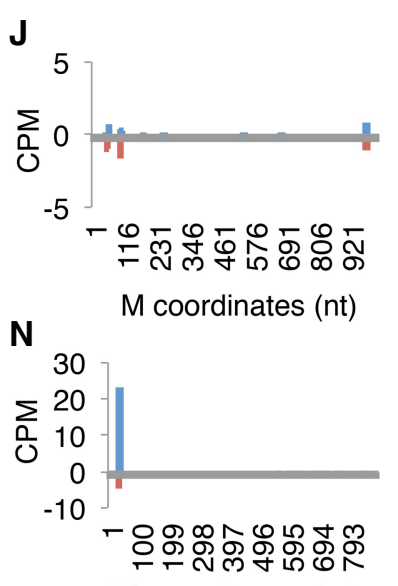

NS coordinates (nt)
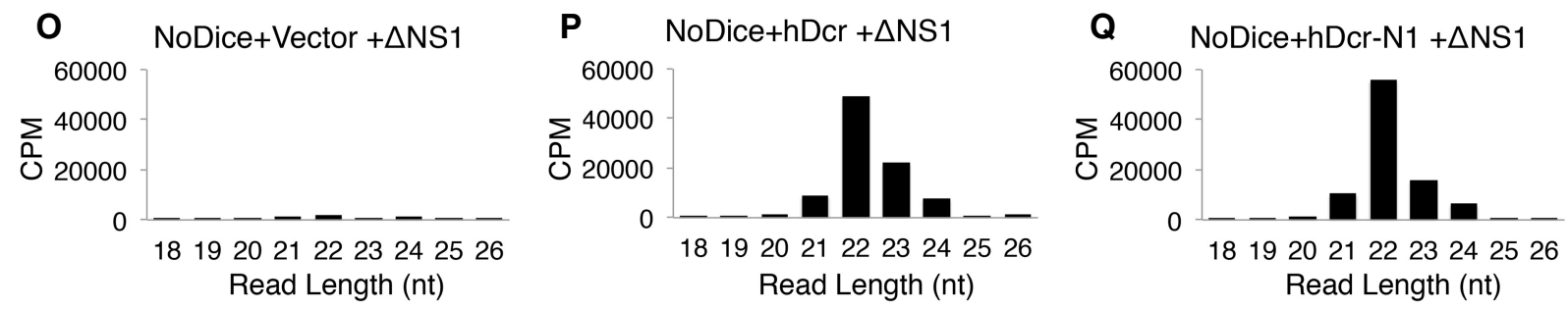

FIGURE 2. Production of IAV-derived siRNAs is dependent on hDcr. NoDice cells were complemented by transfection with the empty pK vector, pK-WT expressing wild-type hDcr, or pK-N1 expressing the hyperactive hDcr-N1 deletion mutant, then infected with an MOI of 0.1 of wild-type PR8 IAV or the $\triangle$ NS1 IAV mutant. ( $A-F)$ The size distribution of virus-aligning sequence reads is plotted in counts per million $(C P M)$ for each host-virus pair, as labeled. Positive and negative sense reads are shown in blue and red, respectively, as before. Note the $4 \times$ greater $y$-axis for panel $F$. ( $G-N)$ Viral siRNAs produced from $\triangle$ NS1-infected, hDcr-transfected NoDice cells from panel $E$ were mapped onto each viral vRNA segment, as in Figure 1C-J. $(O-Q)$ The size distribution of cellular miRNA-aligning small RNA reads recovered from vector, hDcr, or hDcr-N1-complemented NoDice cells was plotted to validate the absence of miRNAs in the control NoDice cells and their rescue in NoDice cells expressing ectopic wild-type or N1 hDcr.

However, overexposure does allow the endogenous hDcr protein to be detected at the predicted size and also suggests that ectopic expression of hDcr leads to a $>10$-fold overexpression relative to wild-type $293 \mathrm{~T}$ cells.
Compilation of data from multiple independent experiments confirmed that the ectopic overexpression of either wild-type or $\mathrm{N} 1 \mathrm{hDcr}$ did not significantly reduce the expression of the IAV HA protein (Fig. 3B,G) or the IAV NP protein 

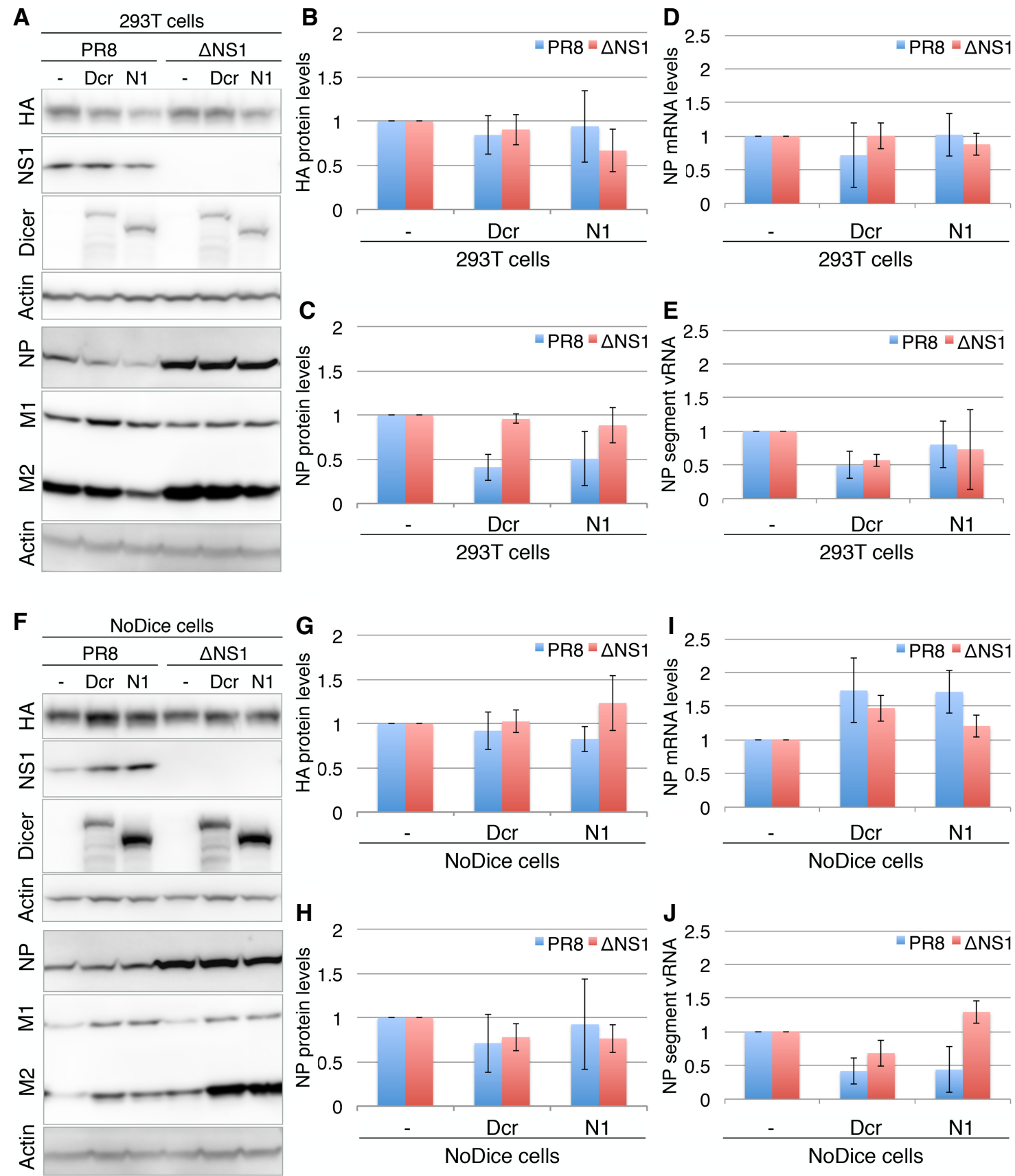

FIGURE 3. Analysis of the potential antiviral function of IAV-derived siRNAs produced in the absence of NS1. Wild-type 293T cells or NoDice cells transfected with the $\mathrm{pK}$ vector (-), pK-hDcr (Dcr), or pK-N1 (N1) were infected with wild-type PR8 or the $\Delta \mathrm{NS} 1$ mutant at an MOI of 1.0. Expression levels of the IAV HA, NS1, NP, M1, and M2 proteins, ectopically expressed hDcr and $\beta$-actin, the latter used as a loading control (one control for HA, $\mathrm{NS} 1$, and hDcr; another for NP and M1/M2, which are from separate western blots and infections), were determined in IAV-infected cells at 24 hpi by western blot in $(A)$ wild-type $293 \mathrm{~T}$ cells or $(F)$ NoDice cells. Western blot band intensities for HA were quantified on western blots from multiple independent repeats, normalized to $\beta$-Actin band levels, and the HA level detected in pK-transfected cells set as one. Quantitation from infected (B) $293 \mathrm{~T}$ cells $(n=5)$ and $(G)$ NoDice cells $(n=6)$. Western blot band intensities for NP were similarly quantified from infected $(C)$ 293T cells $(n=5)$ and $(H)$ NoDice cells $(n=6)$. Viral gene expression was also assayed by IAV strand-specific qRT-PCR, normalized to GAPDH mRNA, with pK-transfected cells set to one. IAV NP mRNA expression levels were measured in $(D)$ 293T cells and (I) NoDice cells. NP segment vRNA production levels were also quantitated in $(E)$ 293T cells and $(J)$ NoDice cells. Average of three independent experiments with SD indicated.

(Fig. 3C,H). Similarly, we did not observe any inhibitory effect on IAV NP mRNA expression (Fig. 3D,I) upon ectopic overexpression of hDcr or the hDcr N1 mutant, in the pres- ence or absence of NS1. However, we did note a trend toward a modest inhibition of NP vRNA expression when wild-type $\mathrm{hDcr}$ was ectopically expressed in either the presence or 
absence of NS1 (Fig. 3E,J). However, this effect was attenuated when the more active $\mathrm{N} 1 \mathrm{hDcr}$ mutant was overexpressed. There also seemed to be a modest inhibition of NP protein expression in $293 \mathrm{~T}$ cells infected with wild-type PR8 that overexpress wild-type hDcr, but not when the $\Delta \mathrm{NS} 1$ mutant was used (Fig. 3C). The fact that this modest inhibition was only seen in the presence of the NS1 protein, which effectively blocks viral siRNA production (Fig. 2), argues that this modest inhibitory effect, if real, is not the result of viral siRNA production. Therefore, we conclude that while loss of NS1 expression does indeed result in the production of a substantially higher level of viral siRNAs of IAV origin (Fig. 2), this does not lead to a significant inhibition in IAV mRNA or protein expression (Fig. 3).

The data presented in Figure 3 were obtained using 293T cells infected at an MOI of 1.0, while the sequencing data presented in Figures 1 and 2 used cells infected at an MOI of 0.1 . To control for the possibility that a lower MOI infection would reveal inhibition by viral siRNAs, we performed infections at an MOI of 0.1, matching the conditions used in Figures 1 and 2. As may be observed in Figure 4, overexpression of wild-type hDcr or $\mathrm{N} 1 \mathrm{hDcr}$ in either wild-type $293 \mathrm{~T}$ cells or in the NoDice mutant cell line again failed to result in any detectable inhibition of the expression of the IAV HA protein.

\section{The lack of viral siRNA function may reflect inefficient RISC-loading}

Why were we unable to observe any obvious inhibitory effect of the IAV-derived siRNAs documented in Figure 2? One possibility is that not enough siRNAs are produced to counteract the high level of viral transcripts generated by the rapidly replicating IAV. In addition, because viral siRNAs can only be produced from the dsRNA templates that accumulate late in the IAV replication cycle, viral siRNAs may also only accumulate late in infection, when the fast moving

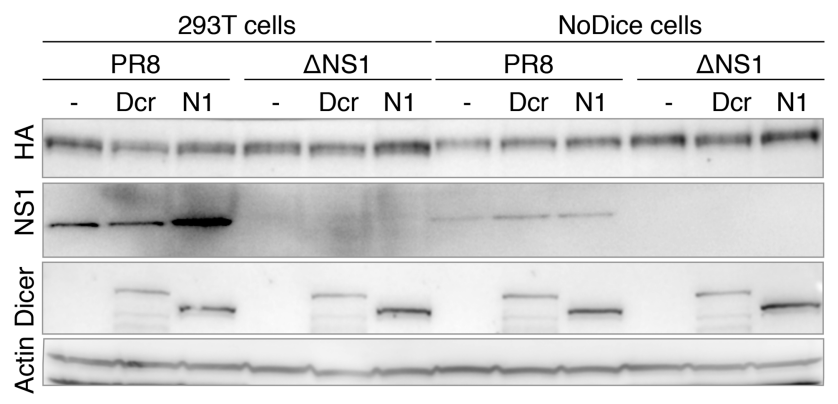

FIGURE 4. Analysis of the antiviral function of IAV-derived siRNAs in cells infected at a low MOI. Similar to Figure 3 except that 293T or NoDice cells transfected with the pK vector (-), pK-hDcr (Dcr), or pK-N1 (N1) were infected with wild-type PR8 or the $\Delta$ NS1 mutant at a lower MOI of 0.1. Expression levels of the viral HA and NS1 protein, the transfected hDcr variant, and cellular $\beta$-actin as a loading control, were analyzed by western blot.
IAV replication cycle is essentially over. Finally, it is possible that IAV-derived siRNAs are simply not efficiently loaded into RISC. To address this latter hypothesis, we performed a RISC immunoprecipitation (IP) using a pan-Ago antibody that binds all forms of the human Ago protein, including the key RISC component Ago2 (Flores et al. 2014). For this purpose, $293 \mathrm{~T}$ cells were infected with the $\triangle \mathrm{NS} 1 \mathrm{IAV}$ mutant at an MOI of 3 to ensure that almost all cells were infected. At $24 \mathrm{hpi}$, the infected cells were harvested, with a portion of the sample subjected to total small RNA extraction, and the rest subjected to RISC IP. IAV-derived small RNA reads, $22 \pm 1 \mathrm{nt}$ in length, could be detected in both the total small RNA sample (Fig. 5A) and in the RISC IP sample (Fig. 5B), thus demonstrating that at least some of the IAV derived siRNAs are indeed loaded into RISC. As expected, we could also detect cellular miRNAs in both the total small RNA sample and in the RISC IP sample, with a significant enrichment in the latter (Fig. 5C,D). Interestingly, when we compared the ratio of RISC bound reads versus total reads for the host cell miRNAs versus the viral siRNAs (Fig. 5E), we found that viral siRNAs are $\sim 6.8$-fold less likely to be RISC associated than the average cellular miRNA. Thus, at least $85 \%$ of the siRNAs observed in Figure $1 \mathrm{~B}$ are not RISC associated and, hence, are incapable of inhibiting IAV mRNA expression. This phenomenon likely explains, at least in part why we failed to see any significant inhibition of IAV gene expression in cells infected by the $\triangle \mathrm{NS} 1$ mutant of IAV (Figs. 3, 4), despite the readily detection of virally derived siRNAs (Fig. 2).

\section{DISCUSSION}

The research described in this manuscript was prompted by a recent paper ( $\mathrm{Li}$ et al. 2016) which reported that loss of NS1 expression resulted in the production of readily detectable levels of viral siRNAs in IAV infected 293T cells, even though these were not detectable in $293 \mathrm{~T}$ cells, or other somatic cell types, infected by wild-type IAV. The authors therefore proposed that not only IAV but also other pathogenic human RNA viruses express VSRs that effectively block the RNAi response to viral infection, thus explaining why siRNAs of viral origin are lacking in virus infected human cells (Pfeffer et al. 2005; Parameswaran et al. 2010; Backes et al. 2014; Bogerd et al. 2014; Girardi et al. 2015) and also why loss of factors such as hDcr does not impact the level of viral gene expression and replication (Bogerd et al. 2014). Curiously, however, this paper did not demonstrate that the IAV mutant lacking NS1 was subject to inhibition by RNAi but rather reported that mouse embryonic fibroblasts lacking a functional Ago2 protein support a significantly higher level of replication of wild-type IAV. As these authors also demonstrated, as noted above, that wild-type IAV, expressing the viral NS1 protein, does not give rise to detectable levels of viral siRNAs, it is unclear how the loss of Ago2 function would promote viral replication, especially as it has previously been reported that cells lacking Ago2 do not support enhanced levels of 
A

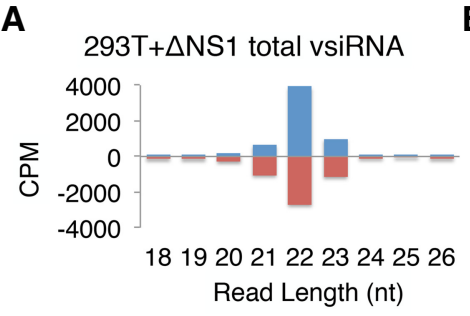

C

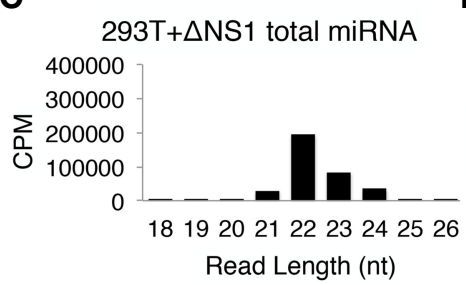

B

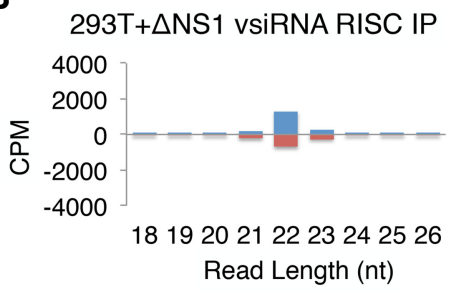

D

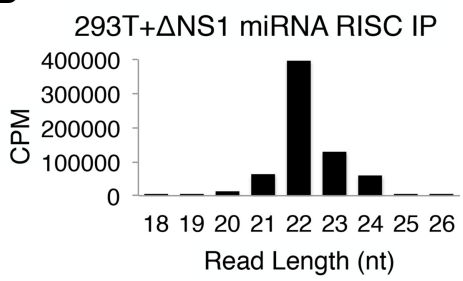

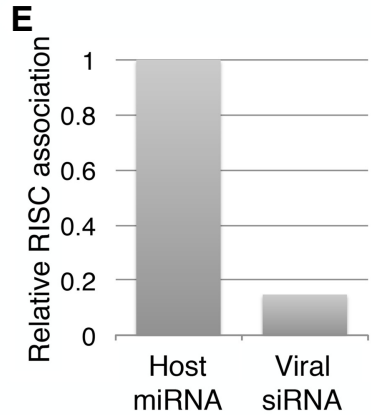

miRNA SiRNA

FIGURE 5. IAV-derived siRNAs are inefficiently loaded into RISC. Wild-type $293 \mathrm{~T}$ cells were infected with the $\Delta$ NS1 IAV mutant at an MOI of 3.0. Infected cells were harvested at $24 \mathrm{hpi}$ and $10 \%$ used for total small RNA isolation (panels $A$ and $C$ ) while the remaining cells were used for RISC immunoprecipitation using an antibody targeting the Ago component of RISC $(B, D)$. The size distribution of small RNA reads is shown for (A) IAV-derived total small RNA reads, $(B)$ RISC immunoprecipitated IAV-derived small RNA reads, $(C)$ known cellular miRNA reads, and $(D)$ RISC immunoprecipitated miRNA reads. $(E)$ The relative RISC association is shown as the proportion of the RISC immunoprecipitated read count divided by the total read count for host miRNAs and viral small RNAs, with the host miRNA RISC-bound ratio set at 1.0.

IAV replication regardless of whether the virus used does or does not express NS1 (Maillard et al. 2016).

Here, we have confirmed several aspects of the published work of Li et al. (2016) yet arrive at the opposite conclusion, i.e., we do not observe inhibition of IAV gene expression by viral siRNAs produced in the absence of NS1. Consistent with the data of Li et al. (2016), we failed to detect a significant level of viral siRNA production in cells infected with wild-type IAV strain PR8 but observed readily detectable levels of viral siRNAs in wild-type $293 \mathrm{~T}$ or A549 cells infected with the IAV PR8 $\triangle$ NS1 mutant (Fig. 1, panels A, B, L and M). As also previously reported (Kennedy et al. 2015; Li et al. 2016), these siRNAs were derived from the $5^{\prime}$ and $3^{\prime}$ termini of the eight IAV genome strands, as expected (Figs. 1C-J, 2G$\mathrm{N})$. Using the hDcr-deficient NoDice cell line derived in this laboratory (Bogerd et al. 2014), we confirmed that viral siRNA production was dependent on $\mathrm{hDcr}$ and, of interest, was substantially boosted when the amino-terminally truncated N1 hDcr mutant was expressed in place of wild-type hDcr (Fig. 2), consistent with our previously reported results (Kennedy et al. 2015). However, despite the detection of fairly high levels of IAV-derived siRNAs in cells expressing ectopic N1 hDcr that were infected with the PR8 $\triangle$ NS1 mutant, we failed to observe a consistent inhibition of IAV protein or RNA expression when compared to cells infected with wild-type IAV, which produce very few siRNAs, or in NoDice cells infected with IAV, which produce no siRNAs at all (Fig. 3). In some cases, we did see evidence for modest inhibition, for example, in the production of NP vRNAs in cells expressing ectopic wild-type hDcr (Fig. 3E,J). However, as this inhibition was attenuated in cells expressing the more active $\mathrm{N} 1$
hDcr mutant, and was not increased in cells infected with the PR8 $\triangle$ NS1 mutant, we do not believe this modest inhibitory effect is related to the level of viral siRNA production. Of note, even though Li et al. (2016) also observed the production of many more IAV siRNAs in cells infected with PR8 $\triangle$ NS1, when compared to wild-type PR8, they also failed to see any inhibition of IAV protein expression by these siRNAs, as documented by closely similar levels of NP expression by both wild-type and $\triangle$ NS1 PR8 after infection of hDcr-expressing cells across several different experiments.

If the observation that the PR8 $\triangle \mathrm{NS} 1$ virus induces a high level of viral siRNA biogenesis in hDcr-expressing cells is indeed correct, as reported previously (Li et al. 2016) and confirmed here, then why does this not significantly inhibit the level of virus replication? One possibility is that the level of siRNA production is simply too low. However, in the experiment documented in Figure 2F, where cells expressing the hDcr N1 mutant were infected at an MOI of 0.1 , we observed that viral siRNAs comprised $\sim 2.3 \%$ of the total assignable small RNA pool which, on a per cell basis, implies that $\sim 23 \%$ of all small siRNAs and miRNAs are of viral origin, which would be expected to be more than sufficient to exert a detectable phenotype. An alternative proposal might be that, while the $\triangle$ NS1 IAV mutant indeed gives rise to readily detectable levels of viral siRNAs, these are not loaded into RISC and hence are not active. In fact, sequencing total versus RISC-associated small RNAs in cells infected with the $\Delta$ NS1 IAV mutant revealed that RISC loading of IAV-derived siRNAs was $\sim 6.8$-fold less efficient than seen for endogenous cellular miRNAs (Fig. 5). Therefore, even if $100 \%$ of endogenous miRNAs are RISC-associated, which we know is not 
the case (Flores et al. 2014), no more than $\sim 15 \%$ of the viral siRNA would be bound by RISC. Why the viral siRNAs are inefficiently loaded into RISC is currently unclear, but this may reflect a limiting level of available unoccupied RISC coupled with the possibility that viral siRNAs are only made at high levels late in the IAV replication cycle, when maximal levels of viral dsRNA replication intermediates are present, and may not yet have undergone RISC loading when the samples were analyzed. In fact, the RNA samples analyzed in this report were all taken at $24 \mathrm{hpi}$, which represents a very late stage of the IAV replication cycle.

Finally, we note that others have reported that mammalian somatic cells encode factors that can block antiviral RNAi responses (Maillard et al. 2016). For example, van der Veen et al. (2018) reported that the RIG-I like receptor LGP2 inhibits Dicer-dependent processing of long dsRNAs in virus infected human cells. However, as viral siRNAs are readily detected in PR8 $\triangle$ NS1 infected cells (Fig. 2F), hDcr clearly remains active in these cells. Conversely, Seo et al. (2013) reported that innate antiviral signaling can result in inhibition of the RNAi machinery in virus infected cells via poly-ADPribosylation of components of RISC. This remains a possible explanation, as infection of cells with an IAV mutant lacking NS1, which normally acts to inhibit a range of antiviral innate immune responses (García-Sastre et al. 1998; Krug and García-Sastre 2013), would be predicted to robustly activate these responses. In conclusion, our data confirm the previous report demonstrating that infection of cells with a NS1-deficient form of IAV, unlike infection with wild-type IAV, does result in the production of a readily detectable level of viral siRNAs (Li et al. 2016). However, these siRNAs do not inhibit IAV gene expression, likely at least in part due to their inefficient loading into RISC.

\section{MATERIALS AND METHODS}

\section{Cells}

NoDice cells (clone 4-25) are Dicer knockout 293T cells generated by gene editing, as previously described (Bogerd et al. 2014). 293T, A549, and canine MDCK cells were obtained from the Duke Cell Culture Facility. 293T, A549, and MDCK cells were cultured in Dulbecco's modified Eagle's medium (DMEM) supplemented with $6 \%$ fetal bovine serum (FBS) and $50 \mu \mathrm{g} / \mathrm{mL}$ gentamicin (Gibco), while NoDice cells were cultured with $9 \%$ FBS. Prior to experiments where $293 \mathrm{~T}$ and NoDice cells were used side-by-side, all cells were cultured with $9 \%$ FBS. To produce NS1-expressing MDCK stable cell lines $\left(\mathrm{NS}^{+} \mathrm{MDCK}\right), \mathrm{NS} 1$ was cloned out of pCAGGS-NS1 (a kind gift from Nicholas Heaton) by PCR using the primers $5^{\prime}$-aaagcggccgctgatccaaacactgtgtcaagc- $3^{\prime}$ and $5^{\prime}$-aaactcgagtcaaacttctgacc taattgttccc- $3^{\prime}$ with Q5 High-Fidelity DNA Polymerase (NEB M0491) and ligated into the NotI/XhoI sites of the lentiviral expression vector pLEX-FLAG (Kennedy et al. 2016). The resulting pLEX-FLAG-NS1 lentivector was packaged as previously described and used to transduce MDCK cells. Transductants were selected with $1.5 \mu \mathrm{g} / \mathrm{mL}$ puromycin for a week, then single cell cloned by limited dilution.

\section{Viruses}

Wild-type IAV (A/Puerto Rico/8/1934, PR8) was produced in embryonated chicken eggs as previously described (Courtney et al. 2017). The $\Delta$ NS1-PR8 and R38A-NS1-PR8 mutant viruses were produced as follows: The $\triangle \mathrm{NS} 1 \mathrm{NS}$ segment was isolated by PCR amplification from $\triangle N S 1-I A V$-infected cell cDNA (a gift from Nicholas Heaton) (García-Sastre et al. 1998), using the primers $5^{\prime}$-ctccgaagttgggggggagcaaaagcagggtgacaaag- $3^{\prime}$ and $5^{\prime}$-tgggccgccggg ttattagtagaaacaagggtgttttt- $3^{\prime}$, then cloned into a Sac I-cut $\mathrm{pDZ}$ vector by Gibson cloning (Quinlivan et al. 2005). This NS segment bears a $525 \mathrm{nt}$ deletion that removes the NS1 gene but leaves the NEP gene intact. The NS segment containing the R38A mutation in the NS1 ORF was produced by site-directed PCR mutagenesis of pDZNS1, using the primers $5^{\prime}$-ctgatcAGCgcgaagccgatcaaggaatggggcatc$3^{\prime}$ and $5^{\prime}$-cttgatcggcttcgcGCTgatcagaaatccctaagagg- $3^{\prime}$ (nucleotides that introduce the mutation shown as capital letters). To rescue mutant virus, the pDZ- $\triangle \mathrm{NS} 1-\mathrm{NS}$ and $\mathrm{pDZ}-\mathrm{R} 38 \mathrm{~A}-\mathrm{NS}$ plasmids were cotransfected with all other viral segments in $\mathrm{pDZ}$, along with pLEX-FLAG-NS1, into 293T cells. The resulting virions in the supernatant media were then amplified by passage in NS1-expressing MDCK cells every 2-3 d for a total of $10 \mathrm{~d}$, in the presence of $1 \mu \mathrm{g} / \mathrm{mL}$ TPCK Trypsin. Single plaques of rescued virus were isolated and amplified through serial passage on $\mathrm{NS}^{+}$MDCK cells. All viruses were titered by plaque assay, WT PR8 on MDCK cells and mutant viruses on $\mathrm{NS}^{+}$MDCK cells, as previously described (Courtney et al. 2017). To validate the identity of the produced mutant viruses, RNA was extracted from virus-infected cells, reverse transcribed using the primer $5^{\prime}$-agcaaaagcagggtgac- $3^{\prime}$, then the NS segment amplified by PCR using primers $5^{\prime}$-agcaaaagcagggtgac- $3^{\prime}$ and $5^{\prime}$-agtagaaacaagggtgtttttatta- $3^{\prime}$. PCR products from the $\triangle$ NS1 virus and the R38A NS1 mutant were both confirmed by DNA sequencing.

\section{Antibodies}

The following antibodies were obtained from commercial sources: hDcr (Santa Cruz, sc-30226); IAV NS1 (Santa Cruz, sc-130568); IAV NP (Clone HT103, Kerafast, EMS010); IAV Matrix (M1/M2, Clone E10, Kerafast, EMS009); $\beta$-Actin (Santa Cruz, sc-47778; Invitrogen, MA5-15739; or Proteintech, 60008-1-Ig); pan-Ago (Abcam, ab57113). Anti-HA (PY102) was a kind gift from Dr. Nicholas Heaton.

\section{Infections}

293T cells and NoDice cells were seeded in 6-well plates and transfected with $2 \mu \mathrm{g} /$ well of the previously described plasmids $\mathrm{pK}$ (empty vector), pK-WT (expressing WT hDcr), or pK-N1 (expressing N1 hDcr) (Kennedy et al. 2015). Each well was split $1 / 6$ into 6-well plates $2 \mathrm{~d}$ post-transfection. At $3 \mathrm{~d}$ post-transfection, cells were washed with PBS, then infected with an MOI of 0.1 or 1.0 of either WT PR8 or the $\triangle$ NS1 IAV mutant diluted in $300 \mu \mathrm{L}$ of serum-free DMEM with $0.25 \%$ BSA. After $1 \mathrm{~h}$ of incubation with occasional rocking, the virus-containing media were removed and replaced with $1 \mathrm{~mL} /$ well recovery media (DMEM with $0.01 \%$ FBS and $0.35 \% \mathrm{BSA}$ ). Cells were harvested $24 \mathrm{~h}$ post-infection for analysis of protein and RNA levels. Western blot band intensity quantifications were performed using Image J 1.5. For small RNA-seq of NoDice cells, infections were scaled up to $60 \mathrm{~mm}$ plates, infections were performed in a $2.5 \mathrm{~mL}$ volume, and recovery at $4 \mathrm{~mL} /$ plate. For 
small RNA-seq of $293 \mathrm{~T}$ cells, infections were done in $15 \mathrm{~cm}$ plates in a $12 \mathrm{~mL}$ volume, and recovery at $15 \mathrm{~mL} /$ plate. For small RNA-seq of IAV-infected A549 cells, infections were performed in one $10 \mathrm{~cm}$ plate per sample at an MOI of 2.5, in an infection volume of $3.8 \mathrm{~mL}$ and using $7.5 \mathrm{~mL}$ of recovery media. RNA samples were again prepared at $24 \mathrm{hpi}$.

For RISC IPs, $\sim 80 \%$ confluent $293 \mathrm{~T}$ cells in six $15-\mathrm{cm}$ plates were infected with $\triangle \mathrm{NS} 1 \mathrm{IAV}$ at an MOI of 3.0 in a $12.5 \mathrm{~mL}$ volume. At $1 \mathrm{hpi}$, the virus was replaced with $16 \mathrm{~mL}$ of recovery media. At $24 \mathrm{hpi}$, cells were washed once with PBS, then $10 \%$ of the cells used for total small RNA sequencing and the rest for RISC IP. RISC IPs were performed as previously described (Flores et al. 2014), using a $0.6 \mathrm{~mL}$ cell pellet.

\section{Small RNA sequencing}

Total small RNA (<200 nt) fractions were extracted from IAVinfected cells using the mirVana microRNA Isolation Kit (Thermo Fisher Ambion AM1560). TruSeq library preparation (TruSeq Small RNA Library Prep Kit, Illumina), Illumina sequencing and data analysis were performed as previously described (Kennedy et al. 2015). Briefly, using Bowtie v0.12.7, reads $<16 \mathrm{nt}$ in length or aligning to known human noncoding RNAs (including Ensembl noncoding RNA database v70, and human functional RNA database v3.4) were discarded. The remaining reads were aligned to known miRNAs (miRBase v20), and the noncoding RNA and miRNA -depleted reads subsequently aligned to the IAV PR8 sequence (Genbank segment accessions nos. EF190971.1EF190978.1). To calculate read size distributions, positive and negative viral or miRBase-aligning read counts per million assignable reads (CPM) were calculated for each read length, using in-house scripts. The read coverage over viral genomic coordinates was also calculated using in-house scripts, using viral-aligning reads in the 20-24 nt size range that have a least one read of the opposite sense with a 2 nt $3^{\prime}$-overhang. Assignable reads are defined as the total number of reads that can be aligned to known human noncoding RNAs or the IAV PR8 or human genome (hg19).

\section{qRT-PCR}

Total RNA was extracted from IAV-infected cells using TRIzol (Thermo Fisher) following the manufacturer's instructions, and subjected to DNase I (NEB M0303) treatment for $~ 30 \mathrm{~min}$, followed by heat inactivation of the enzyme at $75^{\circ} \mathrm{C}$ for $10 \mathrm{~min}$. Reverse transcription (RT) was performed using SuperScript III reverse transcriptase (Thermo Fisher). Strand-specific qRT-PCR was performed as previously described (Kawakami et al. 2011). Briefly, for RT of mRNA, a poly(A)-aligning primer with a nonviral tag (5'-CCAGATCGTTCGAGTCGTtttttttttttt-3') was used; for the negative strand vRNA, we used a primer that aligns to the shared sequence at the $3^{\prime}$ end of all vRNA segments, along with the nonviral tag $\left(5^{\prime}\right.$-CCAGATCGTTCGAGTcgtagcaaaagcaggg- $\left.3^{\prime}\right)$. For both RT primers, the nonviral tag is shown in capital letters. Sybr green qPCR was performed using a nonviral tag-aligning primer $\left(5^{\prime}\right.$-ccagatcgttcgagtcgt- $\left.3^{\prime}\right)$ along with a viral segment specific primer: NP mRNA: $5^{\prime}$-cgatcgtgccttcctttg- $3^{\prime}$, and NP vRNA: $5^{\prime}$-gatgctctgatttcagtggc- $3^{\prime}$. The GAPDH internal control mRNA was quantified using RT products from the poly(A)-aligning primer, with primers $5^{\prime}$-tgggtgtgaaccatgagaag- $3^{\prime}$ and $5^{\prime}$-gatggcatggactgtggtc- $3^{\prime}$.

\section{DATA DEPOSITION}

The deep sequencing data sets generated in this study have been deposited in the GEO database under accession number GSE111572.

\section{ACKNOWLEDGMENTS}

We thank Dr. Nicholas Heaton for reagents used in this work and for advice on experimental design. This research was funded by National Institutes of Health grants R21-AI113098 and R21-AI130574, both to B.R.C. K.T. was supported by National Institutes of Health grant T32-CA009111, while D.G.C. was funded by Marie-Sklodowska Curie Global Fellowship MSCA-IFGF:747810.

Received March 9, 2018; accepted June 12, 2018.

\section{REFERENCES}

Andersson MG, Haasnoot PC, Xu N, Berenjian S, Berkhout B, Akusjärvi G. 2005. Suppression of RNA interference by adenovirus virus-associated RNA. J Virol 79: 9556-9565.

Babiarz JE, Ruby JG, Wang Y, Bartel DP, Blelloch R. 2008. Mouse ES cells express endogenous shRNAs, siRNAs, and other Microprocessor-independent, Dicer-dependent small RNAs. Genes Dev 22: 2773-2785.

Backes S, Langlois RA, Schmid S, Varble A, Shim JV, Sachs D, tenOever BR. 2014. The mammalian response to virus infection is independent of small RNA silencing. Cell Rep 8: 114-125.

Barnes D, Kunitomi M, Vignuzzi M, Saksela K, Andino R. 2008. Harnessing endogenous miRNAs to control virus tissue tropism as a strategy for developing attenuated virus vaccines. Cell Host Microbe 4: 239-248.

Benitez AA, Spanko LA, Bouhaddou M, Sachs D, tenOever BR. 2015. Engineered mammalian RNAi can elicit antiviral protection that negates the requirement for the interferon response. Cell Rep 13: 1456-1466.

Billy E, Brondani V, Zhang H, Müller U, Filipowicz W. 2001. Specific interference with gene expression induced by long, double-stranded RNA in mouse embryonal teratocarcinoma cell lines. Proc Natl Acad Sci 98: 14428-14433.

Bogerd HP, Skalsky RL, Kennedy EM, Furuse Y, Whisnant AW, Flores O, Schultz KL, Putnam N, Barrows NJ, Sherry B, et al. 2014. Replication of many human viruses is refractory to inhibition by endogenous cellular microRNAs. J Virol 88: 8065-8076.

Bucher E, Hemmes H, de Haan P, Goldbach R, Prins M. 2004. The influenza A virus NS1 protein binds small interfering RNAs and suppresses RNA silencing in plants. J Gen Virol 85: 983-991.

Courtney DG, Kennedy EM, Dumm RE, Bogerd HP, Tsai K, Heaton NS, Cullen BR. 2017. Epitranscriptomic enhancement of influenza A virus gene expression and replication. Cell Host Microbe 22: 377-386.e5.

Cullen BR, Cherry S, tenOever BR. 2013. Is RNA interference a physiologically relevant innate antiviral immune response in mammals? Cell Host Microbe 14: 374-378.

Delgadillo MO, Sáenz P, Salvador B, García JA, Simón-Mateo C. 2004. Human influenza virus NS1 protein enhances viral pathogenicity and acts as an RNA silencing suppressor in plants. J Gen Virol 85: 993-999.

Ding SW. 2010. RNA-based antiviral immunity. Nat Rev Immunol 10: 632-644.

Fabozzi G, Nabel CS, Dolan MA, Sullivan NJ. 2011. Ebolavirus proteins suppress the effects of small interfering RNA by direct interaction with the mammalian RNA interference pathway. J Virol 85: 2512-2523. 
Flemr M, Malik R, Franke V, Nejepinska J, Sedlacek R, Vlahovicek K, Svoboda P. 2013. A retrotransposon-driven dicer isoform directs endogenous small interfering RNA production in mouse oocytes. Cell 155: 807-816.

Flores O, Kennedy EM, Skalsky RL, Cullen BR. 2014. Differential RISC association of endogenous human microRNAs predicts their inhibitory potential. Nucleic Acids Res 42: 4629-4639.

García-Sastre A, Egorov A, Matassov D, Brandt S, Levy DE, Durbin JE, Palese P, Muster T. 1998. Influenza A virus lacking the NS1 gene replicates in interferon-deficient systems. Virology 252: 324-330.

Girardi E, Lefèvre M, Chane-Woon-Ming B, Paro S, Claydon B, Imler JL, Meignin C, Pfeffer S. 2015. Cross-species comparative analysis of Dicer proteins during Sindbis virus infection. Sci Rep 5: 10693.

Haasnoot J, de Vries W, Geutjes EJ, Prins M, de Haan P, Berkhout B. 2007. The Ebola virus VP35 protein is a suppressor of RNA silencing. PLoS Pathog 3: e86.

Hannon GJ. 2002. RNA interference. Nature 418: 244-251.

Kawakami E, Watanabe T, Fujii K, Goto H, Watanabe S, Noda T, Kawaoka Y. 2011. Strand-specific real-time RT-PCR for distinguishing influenza vRNA, cRNA, and mRNA. J Virol Methods 173: 1-6.

Kelly EJ, Hadac EM, Greiner S, Russell SJ. 2008. Engineering microRNA responsiveness to decrease virus pathogenicity. Nat Med 14: $1278-1283$.

Kennedy EM, Whisnant AW, Kornepati AV, Marshall JB, Bogerd HP, Cullen BR. 2015. Production of functional small interfering RNAs by an amino-terminal deletion mutant of human Dicer. Proc Natl Acad Sci 112: E6945-E6954.

Kennedy EM, Bogerd HP, Kornepati AV, Kang D, Ghoshal D, Marshall JB, Poling BC, Tsai K, Gokhale NS, Horner SM, et al. 2016. Posttranscriptional $\mathrm{m}^{6} \mathrm{~A}$ editing of HIV-1 mRNAs enhances viral gene expression. Cell Host Microbe 19: 675-685.

Krug RM, García-Sastre A. 2013. The NS1 protein: a master regulator of host and viral functions. In Textbook of influenza, 2nd ed. (ed. Webster RG, et al.), pp. 114-132. Wiley, NY.

Li WX, Li H, Lu R, Li F, Dus M, Atkinson P, Brydon EW, Johnson KL, García-Sastre A, Ball LA, et al. 2004. Interferon antagonist proteins of influenza and vaccinia viruses are suppressors of RNA silencing. Proc Natl Acad Sci 101: 1350-1355.

Li Y, Basavappa M, Lu J, Dong S, Cronkite DA, Prior JT, Reinecker HC, Hertzog P, Han Y, Li WX, et al. 2016. Induction and suppression of antiviral RNA interference by influenza A virus in mammalian cells. Nat Microbiol 2: 16250.

Lichner Z, Silhavy D, Burgyán J. 2003. Double-stranded RNA-binding proteins could suppress RNA interference-mediated antiviral defences. J Gen Virol 84: 975-980.

Lu S, Cullen BR. 2004. Adenovirus VAl noncoding RNA can inhibit small interfering RNA and microRNA biogenesis. $J$ Virol 78: $12868-12876$

Maillard PV, Van der Veen AG, Deddouche-Grass S, Rogers NC, Merits A, Reis ESC. 2016. Inactivation of the type I interferon pathway reveals long double-stranded RNA-mediated RNA interference in mammalian cells. EMBO J 35: 2505-2518.

Mérai Z, Kerényi Z, Kertész S, Magna M, Lakatos L, Silhavy D. 2006. Double-stranded RNA binding may be a general plant RNA viral strategy to suppress RNA silencing. J Virol 80: 5747-5756.

Nejepinska J, Malik R, Filkowski J, Flemr M, Filipowicz W, Svoboda P. 2012. dsRNA expression in the mouse elicits RNAi in oocytes and low adenosine deamination in somatic cells. Nucleic Acids Res 40: 399-413.

Parameswaran P, Sklan E, Wilkins C, Burgon T, Samuel MA, Lu R, Ansel KM, Heissmeyer V, Einav S, Jackson W, et al. 2010. Six
RNA viruses and forty-one hosts: viral small RNAs and modulation of small RNA repertoires in vertebrate and invertebrate systems. PLoS Pathog 6: e1000764.

Perez JT, Pham AM, Lorini MH, Chua MA, Steel J, tenOever BR. 2009. MicroRNA-mediated species-specific attenuation of influenza A virus. Nat Biotechnol 27: 572-576.

Perez JT, Varble A, Sachidanandam R, Zlatev I, Manoharan M, GarcíaSastre A, tenOever BR. 2010. Influenza A virus-generated small RNAs regulate the switch from transcription to replication. Proc Natl Acad Sci 107: 11525-11530.

Pfeffer S, Sewer A, Lagos-Quintana M, Sheridan R, Sander C, Grässer FA, van Dyk LF, Ho CK, Shuman S, Chien M, et al. 2005. Identification of microRNAs of the herpesvirus family. Nat Methods 2: 269-276.

Qiu Y, Xu Y, Zhang Y, Zhou H, Deng YQ, Li XF, Miao M, Zhang Q, Zhong B, Hu Y, et al. 2017. Human virus-derived small RNAs can confer antiviral immunity in mammals. Immunity 46: 992-1004.e5.

Quinlivan M, Zamarin D, García-Sastre A, Cullinane A, Chambers T, Palese P. 2005. Attenuation of equine influenza viruses through truncations of the NS1 protein. J Virol 79: 8431-8439.

Seo GJ, Kincaid RP, Phanaksri T, Burke JM, Pare JM, Cox JE, Hsiang TY, Krug RM, Sullivan CS. 2013. Reciprocal inhibition between intracellular antiviral signaling and the RNAi machinery in mammalian cells. Cell Host Microbe 14: 435-445.

Stein P, Rozhkov NV, Li F, Cárdenas FL, Davydenko O, Vandivier LE, Gregory BD, Hannon GJ, Schultz RM. 2015. Essential role for endogenous siRNAs during meiosis in mouse oocytes. PLoS Genet 11: e1005013.

Tam OH, Aravin AA, Stein P, Girard A, Murchison EP, Cheloufi S, Hodges E, Anger M, Sachidanandam R, Schultz RM, et al. 2008. Pseudogene-derived small interfering RNAs regulate gene expression in mouse oocytes. Nature 453: 534-538.

Umbach JL, Yen HL, Poon LL, Cullen BR. 2010. Influenza A virus expresses high levels of an unusual class of small viral leader RNAs in infected cells. mBio 1: e00204-e00210.

van der Veen AG, Maillard PV, Schmidt JM, Lee SA, DeddoucheGrass S, Borg A, Kjaer S, Snijders AP, Reis ESC. 2018. The RIG-Ilike receptor LGP2 inhibits Dicer-dependent processing of long double-stranded RNA and blocks RNA interference in mammalian cells. EMBO J 37: e97479.

Wang W, Riedel K, Lynch P, Chien CY, Montelione GT, Krug RM. 1999. RNA binding by the novel helical domain of the influenza virus NS1 protein requires its dimer structure and a small number of specific basic amino acids. RNA 5: 195-205.

Wang R, Wang J, Paul AM, Acharya D, Bai F, Huang F, Guo YL. 2013. Mouse embryonic stem cells are deficient in type I interferon expression in response to viral infections and double-stranded RNA.J Biol Chem 288: 15926-15936.

Watanabe T, Totoki Y, Toyoda A, Kaneda M, Kuramochi-Miyagawa S, Obata Y, Chiba H, Kohara Y, Kono T, Nakano T, et al. 2008. Endogenous siRNAs from naturally formed dsRNAs regulate transcripts in mouse oocytes. Nature 453: 539-543.

Wianny F, Zernicka-Goetz M. 2000. Specific interference with gene function by double-stranded RNA in early mouse development. Nat Cell Biol 2: 70-75.

Ylösmäki E, Hakkarainen T, Hemminki A, Visakorpi T, Andino R, Saksela K. 2008. Generation of a conditionally replicating adenovirus based on targeted destruction of E1A mRNA by a cell type-specific microRNA. J Virol 82: 11009-11015.

Zeng Y, Yi R, Cullen BR. 2003. MicroRNAs and small interfering RNAs can inhibit mRNA expression by similar mechanisms. Proc Natl Acad Sci 100: 9779-9784. 

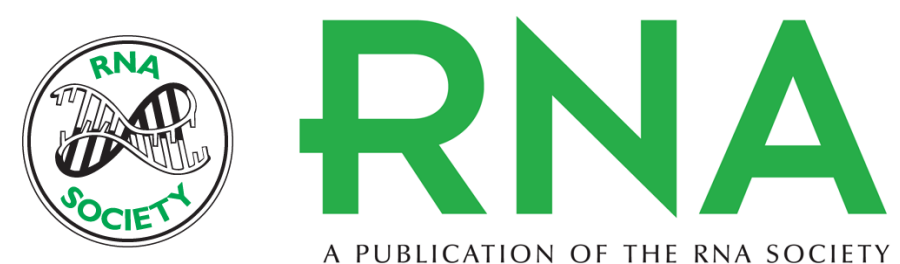

A PUBLICATION OF THE RNA SOCIETY

\section{Influenza A virus-derived siRNAs increase in the absence of NS1 yet fail to inhibit virus replication}

Kevin Tsai, David G. Courtney, Edward M. Kennedy, et al.

RNA 2018 24: 1172-1182 originally published online June 14, 2018

Access the most recent version at doi:10.1261/rna.066332.118

\section{References This article cites 47 articles, 17 of which can be accessed free at: http://rnajournal.cshlp.org/content/24/9/1172.full.html\#ref-list-1 \\ Creative This article is distributed exclusively by the RNA Society for the first 12 months after the Commons full-issue publication date (see http://rnajournal.cshlp.org/site/misc/terms.xhtml). After 12 License months, it is available under a Creative Commons License (Attribution-NonCommercial 4.0 International), as described at http://creativecommons.org/licenses/by-nc/4.0/.}

Email Alerting Receive free email alerts when new articles cite this article - sign up in the box at the Service top right corner of the article or click here.

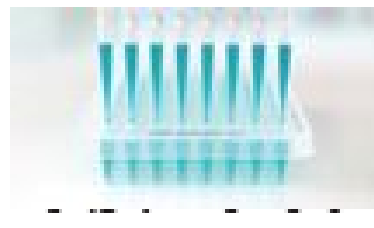

\section{Providing Precise Solutions for} your research.

To subscribe to $R N A$ go to:

http://rnajournal.cshlp.org/subscriptions 